\title{
A ambientalização curricular de programas de Educação Física em universidades federais do Brasil
}

CDD. 20.ed. 796.017

Cae RODRIGUES*

*Centro de Ciências Biológicas e da Saúde,

http://dx.doi.org/10.1590/1807-55092015000300421

\section{Resumo}

0 objetivo do artigo foi analisar evidências de ambientalização curricular em programas de educação física no contexto do ensino superior brasileiro. De acordo com esse objetivo, o "corpus" de análise foi composto pelos planos de ensino de disciplinas que abordam questões ambientais em programas de educação física de Universidades Federais do Brasil. 0 "corpus" foi analisado a partir da Análise Textual Discursiva, metodologia que compreende: a) desmontagem dos textos (unitarização); b) estabelecimento de relações (categorização); c) captação de um novo emergente (metatexto original). As unidades de significado destacadas na etapa de unitarização foram organizadas em categorias pré-definidas a partir das características da Rede ACES para um estudo ambientalizado. A escolha desse referencial ("benchmark") se justifica por sua representatividade diante das produções cientificas no campo ambiental, constituindo-se como significativo (con)texto social atual, trazendo em suas definições o resultado de embates históricos em torno da emergência/legitimação de elementos que constituem os atuais conceitos sobre o "ambiental". Esperar-se-ia, assim, que pelo menos os conceitos chaves de cada categoria fossem contemplados pelas propostas presentes em planos de ensino de disciplinas que propõem um diálogo entre o campo ambiental e o campo da educação física. No entanto, os resultados da pesquisa mostram uma realidade bem diferente, colocando em evidência as práticas esportivas e recreativas na natureza como foco quase que exclusivo das disciplinas que abordam questões ambientais em programas de educação física de Universidades Federais do Brasil. Nos argumentos conclusivos são apresentadas significativas evidências sobre as dimensões dos discursos ambientais que estão sendo incorporados pelos currículos de educação física no âmbito do ensino (superior), assim como novas/"alternativas" perspectivas que emergem nos encontros entre o campo ambiental e o campo da educação física.

Palavras-Chave: Currículo; Ensino superior; Meio ambiente; Ensino escolar; Educação ambiental.

\section{Introdução}

Em parte como consequência da crescente representatividade global do acontecimento ambiental e com base no movimento contemporâneo de ambientalização das mais variadas práticas sociais, há um reconhecimento da comunidade ligada aos setores educacionais de que a educação ambiental é necessária para se alcançar o ideal de sociedades sustentáveis. Nesse sentido, tem sido considerada prioritária a formação de professores aptos a atuarem como agentes de mudança e as instituições de ensino superior desenvolvem papel fundamental na incorporação da educação ambiental nos demais níveis de ensino ${ }^{1}$.

No entanto, apesar das determinaçóes legais e das demandas sociais por uma educação que contemple a dimensão ambiental, estudos apontam uma deficiente formação para a educação ambiental em instituiçóes de ensino superior ${ }^{2-8}$. Essas deficiências são também evidenciadas no Mapeamento da Educação Ambiental em Instituiçóes Brasileiras de Educação Superior ${ }^{9}$. Os estudos apontam como principal entrave para a institucionalização da dimensão ambiental em contextos do ensino superior as dificuldades em torno do complexo processo de emergência de uma base epistemológica para o desenvolvimento do campo ambiental, especialmente considerando seu caráter transversal e interdisciplinar.

Outro ponto de destaque nesse sentido se desenvolve em torno do argumento de que, apesar do 
debate sobre a institucionalização da problemática socioambiental no ensino superior ter começado já há algum tempo, as práticas de ambientalização curricular constituem um processo bem recente e que se desenvolve de maneira bem diferente nos diversos campos disciplinares ${ }^{10}$. A composiçáo do assunto socioambiental no contexto de produçáo das políticas curriculares brasileiras para o ensino superior estaria, assim, diretamente associada às questóes particulares ligadas a definição dos objetivos educacionais e profissionais de cada campo científico-acadêmico específico. Isso significa que a inserçâo desse assunto nos currículos do ensino superior oferece elementos para a edificação de diferentes conjuntos de discursos e significados educacionais sobre a problemática socioambiental, "os quais têm de ser analisados não só a partir das condiçôes contextuais que estáo na base da sua formulação e disseminação, como também das referências, estruturas e dinâmicas que fazem funcionar cada campo em particular"11 (p.125).

Almejando abranger os problemas da ambientalização no ensino superior, algumas iniciativas enfocaram de modo mais direto, especialmente a partir dos anos 1980, diagnósticos do grau de avanço das práticas e programas ambientais em instituiçóes de ensino superior. Um dos movimentos mais influentes nesse sentido foi a constituição da Rede ACES (Rede de Ambientalização Curricular no Ensino Superior). Formada por pesquisadores de 11 universidades de sete países da América Latina e Europa $^{a}$ a Rede reuniu contribuiçóes das instituiçóes participantes e debateu as questôes pertinentes à ambientalizaçáo curricular nas diferentes realidades em que essas instituiçóes se inseriam. Entre os resultados desse processo dialógico destaca-se a elaboração de um diagrama circular que passou a ser a maneira escolhida pela Rede para representar o consenso dos pesquisadores sobre as "características" de um estudo ambientalizado, compreendendo por características um conjunto de atribuiçôes que representa "os âmbitos que devem ser considerados pela avaliação do grau de ambientalização de um currículo, como um conjunto de enfoques que se consideram de forma simultânea ao fazer uma aproximação ao objeto de estudo"12 (p.42). A Rede ACES aparece hoje como um dos principais referenciais no que tange a ambientalização curricular no ensino superior, estando no "mainstream" das produçôes científicas da área, e a definição das 10 características é um marco nos estudos sobre os processos de ambientalizaçáo no ensino superior, constituindo-se enquanto significativo (con)texto social atual sobre o qual é possível analisar como esse processo vem se desenvolvendo em diversos espaços.

Considerando a institucionalizaçáo da dimensão ambiental como importante passo para o crescente desenvolvimento do campo ambiental, incluindo nesse processo a ambientalização dos currículos (inclusive no ensino superior), as açốes da Rede ACES pressupóem que a discussão não gira mais em torno da necessidade ou não da incorporaçáo da dimensão ambiental nos currículos, até porque essa questão está bem clara em documentos importantes ${ }^{\mathrm{b}}$, inclusive em âmbito nacional, como os Parâmetros Curriculares Nacionais ${ }^{13}$ e a Política Nacional de Educação Ambiental ${ }^{14}$. A proposta de avaliação do grau de ambientalização dos currículos preocupa-se já com o próximo passo: como essa incorporação deve ser realizada. Se projetando ao encontro desse potencial "próximo passo", membros da Rede ACES publicaram resultados de pesquisas significativas na última década ${ }^{1,6,8,12,15-17}$.

Pensando já nesse próximo passo o objetivo da pesquisa apresentada nesse artigo foi analisar as matrizes curriculares de programas de Educação Física de Universidades Federais do Brasil buscando elementos que evidenciassem processos de ambientalização curricular na Educação Física no contexto do ensino superior brasileiro. Tal investigação se justifica pela crescente necessidade de uma "história escrita" associada aos processos de ambientalizaçáo curricular na Educação Física, especialmente considerando a importância de um olhar analítico sobre as contínuas e constantes inovaçôes do currículo. A importância dessa história escrita também se justifica pela consideração de que qualquer análise de desenvolvimentos anteriores pode fornecer significativos quadros de referência ("benchmark") e visóes/"insights" relevantes para o planejamento, implementação, conteúdo, processos e avaliação de novas/diferentes versóes de currículos ambientalizados na educação (física). Em outras palavras, há necessidade de um monitoramento crítico e reflexivo sobre o processo de ambientalização curricular na Educação Física como prática educativa e como discurso, tornando-se possível o acompanhamento de sua evolução, seus mitos, realizações, problemas, resultados e consequências, assim como um "arquivamento" de tais memórias para servirem de referência futura $^{18}$. Isso se torna ainda mais representativo se considerarmos as multiplicidades e a rápida evolução de conceitos associados às construçóes discursivas do campo ambiental, favorecendo a emergência de discursos que se apropriam de certos "chavôes" discursivos para se "modernizarem" e, assim, se legitimarem como teorias/práticas atuais/inovadoras quando, na 
verdade, reproduzem símbolos de dominância em práticas de "greenwashing"c

Por fim, a temática geral de ambientalização curricular na qual a proposta da pesquisa se enquadrou vem sendo desenvolvida por outros grupos de pesquisa nacionais (por exemplo, Grupo de Estudos em Formação de Professores, Ambientalização Curricular e Educação em Ciências - UFSCar) e internacionais (por exemplo, "Education", Environment and

\section{Método}

De acordo com o objetivo da pesquisa, o "corpus" de análise (conjunto de textos selecionados a partir de sua representatividade ao tema) foi composto pelos planos de ensino de disciplinas que abordam questôes ambientais em programas de Educação Física de Universidades Federais do Brasil. A busca por essas disciplinas foi realizada pelas seguintes etapas:

- Pesquisa em sítios eletrônicos das Universidades Federais do Brasil. Nessa pesquisa buscaram-se palavras-chave ("natureza", "meio ambiente", "eco...", "esportes de aventura”) que poderiam caracterizar abordagens que incluíssem, de alguma maneira, as relaçóes entre as questóes ambientais e a Educação Física;

- Envio de mensagens eletrônicas para os departamentos e coordenações de cursos de Educação Física de Universidades Federais do Brasil. Na mensagem foi perguntado se havia alguma disciplina na matriz curricular do curso que abordasse, de alguma maneira, questóes ambientais. Nos casos em que as mensagens não foram respondidas a etapa foi repetida três vezes;

- Envio de mensagem eletrônica para coordenadores dos cursos de Educação Física das Universidades Federais do Brasil e para os professores responsáveis pelas disciplinas solicitando planos de ensino e fichas de caracterização. Nos casos em que as mensagens não foram respondidas a etapa foi repetida três vezes.

O "corpus" foi analisado a partir da Análise Textual Discursiva, metodologia que compreende três ciclos:

1. Desmontagem dos textos: também denominado de processo de unitarização, implica examinar os materiais em seus detalhes, fragmentando-os no sentido de atingir unidades constituintes, enunciados referentes aos fenômenos estudados;

2. Estabelecimento de relaçóes: processo denominado de categorização, implicando construir relaçôes entre as unidades de base, combinando-as e classificando-as no sentido de compreender como
Sustainability Faculty Research Group - Monash University, Austráliad e o grupo Complex do Departamento de Didáctica de la Matemática y las Ciencias Experimentales de la Universidad Autónoma de Barcelona ${ }^{e}$, além da própria Rede ACES). Dessa maneira, os resultados da pesquisa foram enquadrados no contexto maior dessa rede de pesquisas sobre a temática, contribuindo para a construção de um diálogo internacional e multidisciplinar.

esses elementos unitários podem ser reunidos na formação de conjuntos mais complexos, as categorias;

3. Captando o novo emergente: a intensa impregnação nos materiais da análise desencadeada pelos dois estágios anteriores possibilita a emergência de uma compreensão renovada do todo. $\mathrm{O}$ investimento na comunicação dessa nova compreensão, assim como de sua crítica e validação, constituem o último elemento do ciclo de análise proposto. $\mathrm{O}$ metatexto resultante desse processo representa um esforço em explicitar a compreensão que se apresenta como produto de uma nova combinação dos elementos construídos ao longo dos passos anteriores ${ }^{19}$ (p.191).

$\mathrm{O}$ processo de categorização pode ser realizado a partir de categorias definidas "a priori”, quando se conhecem de antemão os grandes temas da análise, ou a partir da construção de categorias emergentes "com base nos conhecimentos tácitos do pesquisador, sempre em consonância com os objetivos da pesquisa"19 (p.195). Na presente pesquisa a categorização foi definida a partir da construção de categorias definidas "a priori", refletindo as 10 características elaboradas pela Rede ACES para a identificação de estudos ambientalizados. Desse modo, as seguintes categorias foram formadas: 1) Compromisso com a transformação das relaçóes Sociedade-Natureza; 2) Complexidade; 3) Ordem disciplinar: flexibilidade e permeabilidade; 4) Contextualização; 5) Levar em conta o sujeito na construção do conhecimento; 6) Considerar os aspectos cognitivos e afetivos, éticos e estéticos; 7) Coerência e reconstrução entre teoria e prática; 8) Orientação prospectiva de cenários alternativos; 9) Adequação metodológica; 10) Espaços de reflexão e participação democrática. A escolha desse referencial como "benchmark" (marco teórico sobre o qual será realizada a análise do "corpus") não significa que seja "exemplar" ou um padrão que deva ser necessariamente seguido, mas justifica-se 
pela força (reconhecimento/legitimação pelos atores do campo) que possui no atual cenário ambiental. Esses indicadores podem (e quase que certamente irão) mudar em momentos futuros, porém a pesquisa foi situada no presente contexto histórico/cultural e buscou referências significativas desse contexto.

Com base nas categorias pré-definidas as unidades de significado de cada plano de ensino ("corpus" de análise) foram destacadas (processo de unitarizaçáo primeiro ciclo da Análise Textual Discursiva). Cada unidade foi representada pela letra $\mathrm{O}$ (sendo unidade referente ao quadro de objetivos do plano de ensino), E (sendo unidade referente à ementa), C (sendo unidade referente ao quadro de conteúdos) ou M (sendo unidade referente ao quadro de metodologias de ensino). A letra é sempre seguida pelo número do plano de ensino ao qual a unidade pertence e pelo número da unidade, respectivamente. Para exemplificar, se a unidade de significado for referente ao quadro de objetivos do plano de ensino 1 (definido pela ordem de análise), a primeira unidade (em ordem de ocorrência) foi codificada como unidade O-1.1, a segunda unidade como O-1.2, e assim por diante. Agora, se a unidade for referente à ementa do plano de ensino 1, a primeira unidade foi codificada como unidade E-1.1, a segunda unidade como E-1.2, e assim por diante. Considerando agora uma unidade do quadro de objetivos do plano de ensino 2, a primeira unidade foi codificada como unidade O-2.1, a segunda unidade como O-2.2, e assim por diante.

\section{Resultados}

\section{Características da Rede ACES e dimensões ambientais de disciplinas curriculares em programas de Educação Física no ensino superior brasileiro}

Foram consideradas para a análise dos processos de ambientalização curricular na Educação Física em contextos de ensino disciplinas que propóem discussóes em torno das questôes ambientais em cursos/programas de Educação Física no ensino superior brasileiro. Reconhecendo que os processos de ambientalizaçáo no contexto do ensino abrangem um escopo de atividades que não se restringem às disciplinas curriculares, incluindo, por exemplo, projetos de pesquisa/extensão e a transformação do próprio espaço físico/material das instituiçōes de ensino, a opção pela análise das disciplinas curriculares justifica-se por sua relevância como representação de processos geo-culturais/históricos/
Antes de apresentar os resultados dessa análise é importante ressaltar o reconhecimento de suas limitaçóes, considerando que o "texto escrito" evidencia apenas parcialmente o "contexto práxico" das propostas presentes nos planos de ensino. $\mathrm{O}$ texto escrito pode, assim, "valorizar" (especialmente pela apreensão de certos "chavôes" discursivos) práticas que não conseguem alcançar os objetivos propostos em sua cotidianidade ou, por outro lado, pode não conseguir expressar na escrita a amplitude de acontecimentos que ocorrem na cotidianidade da prática. As consideráveis distinçôes entre os planos de ensino das diferentes Universidades Federais do Brasil também se apresenta como fator limitante nesse sentido. Longe de haver certo padrão, de alguma forma esperado considerando que todas fazem parte do sistema federal de ensino superior brasileiro, cada plano de ensino tem seu próprio formato sendo que enquanto alguns apresentam informaçóes detalhadas sobre a disciplina, chegando a ter até seis páginas, outros apresentam apenas informações básicas resumidas em uma única página.

Consideradas as limitações, os planos de ensino apresentam significativas evidências sobre as dimensóes dos discursos ambientais que estáo sendo incorporados pelos currículos de Educaçáo Física no âmbito do ensino (superior), assim como novas/diferentes perspectivas que emergem nos encontros entre o campo ambiental e o campo da Educação Física.

políticos resultantes de embates de força que fazem parte da constituição/legitimaçâo das estruturas sociais. Esse processo é uma via de mão dupla, pois ao mesmo tempo em que as disciplinas curriculares representam/ reproduzem os resultados dos históricos embates de força que ocorrem em diferentes espaços de disputa também contribuem para a evolução desses embates construindo/legitimando (como capital simbólico formalizado/institucionalizado) novos/diferentes símbolos diante das particularidades do campo científico/ acadêmico. Nesse sentido, optou-se pela análise das matrizes curriculares das Universidades Federais do Brasil, compreendendo que representam os embates de força em âmbito nacional.

Das 44 Universidades Federais do Brasil que possuem curso de Educação Física foi possível a identificação de 15 instituiçôes que possuem disciplinas que abordam as relaçốes entre Educação Física 
e meio ambiente, sendo que 11 foram identificadas diretamente pela pesquisa nos sítios eletrônicos e quatro por respostas às mensagens eletrônicas enviadas para as coordenaçóes e departamentos dos cursos de Educação Física. Das universidades restantes, 21 disponibilizam a matriz curricular do curso de Educação Física nos sítios eletrônicos, mas não foi possível a identificação de nenhuma disciplina com as características procuradas pela pesquisa. Dessas, duas confirmaram por mensagem eletrônica que realmente não possuem disciplinas com essas características, uma justificou por mensagem eletrônica que a matriz curricular do curso estava passando por reformulaçóes e que há previsão na nova matriz (sujeita à aprovação) para inclusão de uma disciplina com essas características e as outras 18 não responderam as mensagens eletrônicas enviadas. Por fim, das oito universidades que não disponibilizam matrizes curriculares do curso de Educação Física nos sítios eletrônicos, uma justificou por mensagem eletrônica que a matriz curricular do curso estava passando por reformulaçôes e que não havia ainda previsôes sobre as disciplinas da nova matriz e sete não responderam as mensagens eletrônicas enviadas.

O QUADRO 1 mostra os resultados dessa pesquisa:

QUADRO1-Disciplinas de cursos de Educação Física em Universidades Federais do Brasil queabordam questões ambientais e as atividades na natureza.

\begin{tabular}{|c|c|c|c|}
\hline \multicolumn{4}{|l|}{ Bloco 1} \\
\hline $\begin{array}{l}\text { Nome da } \\
\text { Instituiçấo }\end{array}$ & Formaçáo & Nome da disciplina & Caráter da disciplina \\
\hline UFSCar & Lic. em EF & $\begin{array}{l}\text { Esportes na Natureza } \\
\text { Ecomotricidade }\end{array}$ & $\begin{array}{l}\text { Optativa } \\
\text { Optativa }\end{array}$ \\
\hline UFPel & $\begin{array}{l}\text { Lic. em EF (Int. e Not.) } \\
\text { Bach. e Lic. em EF } \\
\text { Bach. e Lic. em EF }\end{array}$ & $\begin{array}{l}\text { Educação Física e Meio Ambiente } \\
\text { Atividades Físicas de Ação na Natureza } \\
\text { Esportes de Aventura }\end{array}$ & $\begin{array}{l}\text { Obrigatória } \\
\text { Obrig. Bach./ Opt. Lic. } \\
\text { Optativa }\end{array}$ \\
\hline UFPE & Lic. e Bach. em EF & $\begin{array}{l}\text { Fundamentos Teórico-Metodológicos } \\
\text { das Atividades Físicas e Esportivas na } \\
\text { Natureza }\end{array}$ & Obrigatória \\
\hline UFSC & Lic. e Bach. em EF & $\begin{array}{l}\text { Teoria e Metodologia dos Esportes de } \\
\text { Aventura }\end{array}$ & Obrigatória \\
\hline UFAL & $\begin{array}{l}\text { Lic. em EF } \\
\text { Bach. em EF }\end{array}$ & Atividades Físicas na Natureza & Eletiva \\
\hline UNIFAP & Lic. Plena em EF & Recreação e Lazer Integrada a Natureza & Obrigatória \\
\hline UFU & Lic. e Bach. em EF & Esportes de Aventura & Obrigatória \\
\hline UFTM & Bach. em EF & $\begin{array}{l}\text { Fundamentos dos Esportes III - Esportes } \\
\text { de Aventura }\end{array}$ & Obrigatória \\
\hline FURG & Lic. em EF & Ecologia & Obrigatória \\
\hline UTFPR & Bach. em EF & Esportes de Aventura & Optativa \\
\hline UFC & Lic. e Bach. em EF & Esportes de Aventura & Optativa \\
\hline \multicolumn{4}{|l|}{ Bloco 2} \\
\hline UFMG & Lic. e Bach. em EF & $\begin{array}{l}\text { Tópicos em Educação Física e Esportes C: } \\
\text { Atividades de Lazer na Natureza }\end{array}$ & Optativa \\
\hline UFSM & Lic. em EF & $\begin{array}{l}\text { Laboratório de Atividades Contemporâ- } \\
\text { neas }\end{array}$ & Obrigatória \\
\hline UNIFESP-BS & Bach. em EF & $\begin{array}{l}\text { Fundamentos das Atividades Físicas e } \\
\text { Esportivas VII - Práticas Alternativas e } \\
\text { Integrativas }\end{array}$ & Obrigatória \\
\hline UFRRJ & Lic. em EF & Educação Física Escolar I & Obrigatória \\
\hline
\end{tabular}

** No "Bloco 1" são apresentadas disciplinas identificadas por pesquisa direta nos sítios eletrônicos das universidades;

no "Bloco 2" são apresentadas disciplinas identificadas por meio de mensagens eletrônicas enviadas pelas coordenações e departamentos dos cursos de Educação Física das universidades consultadas.

* Os termos "Licenciatura", "Bacharelado", "Educação Física", "Integral", "Noturno", "Obrigatória" e "Optativa" estão abreviados pelas siglas "Lic.", "Bach.", "EF", "Int.", "Not.", "Obrig." e "Opt.", respectivamente". 
Como pode ser observado no QUADRO 1 foram identificadas 18 disciplinas em 15 instituições que abordam as relaçóes entre Educação Física e meio ambiente, considerando que duas instituiçóes possuem mais do que uma disciplina com essas características em suas matrizes curriculares. Dessas
18 disciplinas tivemos acesso a 14 planos de ensino (disponibilizados nos próprios sítios eletrônicos das universidades ou enviados por mensagem eletrônica pelos professores responsáveis pelas disciplinas). Para facilitar a análise os planos de ensino (QUADRO 2) foram numerados na seguinte ordem:

QUADRO 2 - Organização numeral dos planos de ensino que constituem o “corpus” da pesquisa.

\begin{tabular}{|l|l|}
\hline Plano 1 & Atividades Físicas de Ação na Natureza - UFPel \\
\hline Plano 2 & Educação Física e Meio Ambiente - UFPel \\
\hline Plano 3 & Educação Física e Meio Ambiente - Noturno - UFPel \\
\hline Plano 4 & Esportes de Aventura - UFPel \\
\hline Plano 5 & Ecologia - FURG \\
\hline Plano 6 & Atividades Físicas na Natureza - UFAL \\
\hline Plano 7 & Educação Física Escolar I - UFRRJ \\
\hline Plano 8 & Tópicos em Educação Física e Esportes C: Atividades de Lazer na Natureza - UFMG \\
\hline Plano 9 & Ecomotricidade - UFSCar \\
\hline Plano 10 & Esportes na Natureza - UFSCar \\
\hline Plano 11 & Esportes de Aventura - UFU \\
\hline Plano 12 & Recreação e Lazer Integrada a Natureza - UNIFAP \\
\hline Plano 13 & Fundamentos das Atividades Físicas e Esportivas VII - Práticas Alternativas e Integrativas - UNIFESP-BS \\
\hline Plano 14 & Esportes de Aventura - UTFPR \\
\hline
\end{tabular}

Nas próximas páginas será apresentada a organização do processo de categorização das unidades de significado, ou seja, como as unidades de significado destacadas dos planos de ensino ("corpus" de pesquisa) foram organizadas diante das categorias pré-definidas a partir das características da Rede ACES. Há em cada categoria uma breve apresentação dos elementos considerados essenciais pela Rede ACES para sua constituição (elementos fundadores), seguido da descrição de elementos específicos associados às unidades de significado destacadas do "corpus" de análise que se enquadram no "universo"/contexto de tal categoria. Considerando as restriçóes de paginação do presente artigo e a consequente impossibilidade de apresentar todas as unidades de significado destacadas na análise dos planos de ensino, serão ressaltadas algumas representativas unidades de significado na apresentação de cada categoria. As associaçóes entre "elementos fundadores" de cada categoria e as unidades de significado que se destacam diante desses elementos formarão o alicerce para a emergência de uma compreensão renovada do todo (terceiro ciclo da Análise Textual Discursiva). O "metatexto" resultante desse processo será apresentado na última parte do presente artigo (discussão).

\section{Categoria 1- Compromissocoma transformação} das relações Sociedade-Natureza

Essa característica está diretamente associada às transformações das condiçóes de nossa existência em sociedade, interligando os campos de ação e do pensamento humano e os pontos de tensionamento na relação humana com a natureza. Entre as contribuiçóes dos pesquisadores da Rede ACES destaca-se a importância do contexto social como referência na produçáo de "formas de pensar"; a participaçâo para incidir nas políticas que tendem a melhorar a qualidade de vida da sociedade; a construção (reconstrução) de uma visão de mundo que gere açóes transformadoras; práticas sociais que explicitem e reduzam relaçôes discriminatórias e predatórias; o compromisso com a mudança rumo à sustentabilidade; a preparação dos alunos para enfrentar as questôes ambientais.

Considerando especificamente a presença de conteúdos que abordem problemáticas das relaçóes Sociedade-Natureza destacam-se nos planos de ensino, além de conteúdos especificamente centrados em tal problemática, conteúdos que estariam associados aos jogos de sensibilizaçáo (que têm como objetivo central a sensibilização pelas relaçôes entre 
os seres humanos e desses com o mundo), ao esporte (que podem ser desenvolvidos objetivando estimular visóes questionadoras de padróes modernos) e às atividades na natureza (que podem estimular encontros críticos entre o ser humano e a natureza). Todos os planos de ensino analisados apresentaram entre suas ementas, objetivos ou conteúdos elementos que vão ao encontro de pelo menos uma dessas propostas. A seguir são apresentadas três das 32 unidades originalmente destacadas nessa categoria que ressaltam os elementos específicos descritos nesse parágrafo: Capacitar o futuro profissional da área da Educação Física a: conceituar Educação ambiental, Meio Ambiente, ecologia e Educação Física compreendendo suas relaçôes. Reconhecer os principais conceitos apresentados e aplicá-los em problemas práticos. Identificar e compreender as questôes ambientais e relacioná-las com a Educação Física. Apresentar proposiçóes para os problemas ambientais através do contexto de atuação da Educação Física e participar das atividades propostas (unidade O-2.1).

Educação Física e Meio ambiente: as relaçôes entre Ser humano e Natureza; interfaces com a Educação Ambiental; jogos de Sensibilização à Natureza (unidade E-10.2).

Propiciar aos acadêmicos do Curso de Educação Física, informaçôes básicas a respeito dos diferentes esportes de aventura e/ou radicais, realizados de maneira lúdica ou competitiva, bem como também, promover maior conscientização da realização dos mesmos em contato com a natureza, sem agredi-la (unidade O-11.1).

Outro tópico considerado nessa categoria são as açóes que apareçam na dinâmica de justificaçāo do respeito à Sociedade e à Natureza. Nesse sentido podemos destacar nos planos de ensino conteúdos que estariam associados a açóes que buscam a relação harmoniosa entre ser humano e natureza, além de práticas sociais que explicitam e reduzem relaçôes discriminatórias e predatórias, como, por exemplo, atividades que focam questóes relacionadas ao direito à saúde e ao lazer, estimulando discussões críticas sobre a inclusão de populaçôes marginalizadas. A seguir são apresentadas duas 32 unidades destacadas nessa categoria que ressaltam os elementos específicos descritos nesse parágrafo:

Discutir as interfaces entre Educação Física e Educação Ambiental, destacando atitudes e valores de respeito e compromisso com o meio-ambiente (unidade O-10.2).
Compreender o tripé Lazer, Recreação e Turismo

Esportivo em suas diferentes relaçôes e atuaçôes na sociedade, analisando neste contexto o tempo livre, o ócio e seus enredamentos com o trabalho no sistema do capital (unidade O-12.1).

Entre as pertinentes discussóes que emergem da associação dos elementos fundadores dessa categoria com elementos específicos das unidades destacadas do "corpus" de análise uma chama especial atenção por mexer com uma característica histórica marcante da Educação Física: a discussão sobre possibilidades e limitações de propostas pedagógicas na Educação Física. Posta de maneira bem ampla a discussão gira em torno da seguinte questão: ao mesmo tempo em que o jogo, o esporte e atividades em contextos de lazer têm sido usados desde os primórdios da área como "instrumento" para o desenvolvimento físico-militarista/higienista ${ }^{20}$ e para fins compensatórios, moralistas e utilitaristas ${ }^{21}$, também apresentam relevantes características para o potencial desenvolvimento pedagógico diante de abordagens críticas.

Do ponto de vista cultural, o jogo, o esporte e as atividades em contextos de lazer apresentam-se como meios de "educação lúdica" para a aprendizagem de habilidades e a incorporação de valores a partir de experiências espaço-temporais corpóreas/ perceptivas que se manifestam pela motricidade entre indivíduos que interagem uns-com-os-outros e com-o-mundo. Por outro lado, partindo da lógica hegemônica/higienista associada às influências do Movimento Ginástico Europeu no Brasil ${ }^{20}$ e à ênfase materialista (foco no desenvolvimento "físico") associada às influências militaristas, a Educação Física brasileira carrega uma herança secular de abordagens que reproduzem, pela naturalização de valores e normas dominantes, as formas de controle social ${ }^{22}$.

Dessa forma, mesmo reconhecendo nos planos de ensino analisados conteúdos que abordam problemáticas das relaçóes sociedade-natureza e propostas de açóes que aparecem na dinâmica de justificação do respeito à sociedade e à natureza, é necessário destacar que as possibilidades e limitaçóes de propostas pedagógicas que se desenvolvem em torno de jogos, esportes e atividades em contextos de lazer precisam ser sempre discutidas e relevadas levando em consideração a significativa questão posta nos parágrafos anteriores.

\section{Categoria 2 - Complexidade}

Todos os critérios que se encontram nessa categoria estão associados à valorizaçáo do diálogo ou à construção do conhecimento a partir da complementaridade e 
não a partir da fragmentação e da divisão. Os elementos fundadores da categoria foram desenvolvidos a partir da "teoria da complexidade" de Edgar Morin que, aliás, aparece com frequência no campo ambiental em contextos "latinos" (América Latina e países do sul da Europa Ocidental, especialmente Portugal e Espanha). Entre as características fundamentais da teoria destacam-se: a) a caracterizaçáo dos fenômenos como sistemas; b) uma abordagem hologramática para processos de ensino e de aprendizagem; c) a perspectiva dialógicaf.

Nessa perspectiva, algumas unidades apresentam matérias que recontextualizam a disciplina; princípios associados à visão sistêmica, dialógica e hologramática da relação ser humano-natureza; consideraçóes à interpretação complexa da realidade; e, por fim, análise das causas e efeitos dos problemas socioambientais. A seguir sáo apresentadas duas das sete unidades destacadas nesse sentido:

Conceitos básicos em ecologia. Caracterização básica da Biosfera: aspectos evolutivos e estruturais. A hipótese Gaia. Ecossistemas: organização e dinâmica. A pressão antropogênica no meio: aspectos sociais e econômicos. Impactos antrópicos globais: causas e consequências. Sustentabilidade. Caracterização geral da estrutura de política e controle ambiental no Brasil (unidade E-5.1).

Compreender a ecomotricidade e sua fundamentação na Ciência da Motricidade Humana, na Pedagogia Dialógica e na Educação Ambiental Crítica (unidade O-9.1).

Apesar da identificação nos planos de ensino de algumas unidades que se associam a características fundadoras dessa categoria não há nenhuma referência à "teoria da complexidade" ou mesmo à "complexidade" como referida por Edgar Morin e seus seguidores. Este é um dado relevante considerando a frequência em que essa referência aparece em publicaçóes do campo ambiental, incluindo em contextos latinos.

\section{Categoria 3 - Ordem disciplinar: flexibilidade e permeabilidade}

Essa categoria apresenta critérios que buscam identificar a reorganização do currículo acadêmico por meio da abertura à reflexáo crítica a partir da adequação dos conteúdos educativos ao contexto sociocultural, possibilitando o diálogo com atividades associadas a diferentes ideias e posiçôes filosóficas. Nesse contexto destacam-se a participação de diferentes profissionais ou áreas de conhecimento e a incorporaçáo de temáticas emergentes e diversificadas. A seguir são apresentadas quatro das 19 unidades de significado destacadas na pesquisa que evidenciam essas características: Educação Física, ecologia, Meio Ambiente e educação ambiental: fundamentação e consideraçôes; a educação ambiental e a formação de professores; a Política Nacional de Educação Ambiental; a educação ambiental e a Educação Física: Educação Física e Meio Ambiente; Educação Física, educação ambiental e transversalidade (unidade C-2.1).

As transformaçóes no meio rural e urbano e suas implicaçóes para a ecomotricidade; as transformaçôes no mundo do trabalho e suas consequências para a ecomotricidade; perspectivas da ecomotricidade e suas relaçóes com a educação e educaçáo física em espaços educativos (unidade E-9.2).

Ecomotricidade, trans e interdisciplinaridade (unidade E-9.3).

Elementos da Cultura, Natureza, Ócio, Trabalho, Tempo, Atitude, Diferenças Sociais (unidade C-12.2).

Considerando a natureza dessa categoria diante das particularidades do campo da Educação Física, os jogos cooperativos e os jogos tradicionais poderiam ser interessantes caminhos potenciais para o diálogo com atividades associadas a diferentes ideias e posiçóes filosóficas. Segundo Osborne e BAtista ${ }^{23}$, os jogos cooperativos e os jogos tradicionais carregam uma importância singular entre os elementos particulares da Educação Física que podem desempenhar um papel "ativo" na inserção da dimensão ambiental na área. Os chamados "jogos tradicionais” valorizam a cultura regional e o legado de geraçóes passadas e são considerados essenciais para a valorização das culturas tradicionais (rudimentares, não no sentido de "pouco desenvolvidas”, mas sim primordiais/originárias) ${ }^{24}$. Já os jogos cooperativos são caracterizados como "[...] jogos com uma estrutura alternativa onde os participantes jogam com o outro, e não contra o outro. Joga-se para superar os desafios do próprio jogo e o não o outro, joga-se por gostar do jogo" 25 (p.66). Nesse sentido, tanto os jogos tradicionais como os cooperativos oferecem interessantes possibilidades de diálogos na diversidade em contextos de "com-vivência"g, potencialmente estimulando a incorporação de temáticas emergentes e diversificadas. No entanto, apesar do destaque dado a essas atividades em publicações da Educação Física, inclusive em propostas de inserção da dimensão ambiental na área, essas não aparecem nos planos de ensino analisados. 


\section{Categoria 4 - Contextualização}

Considerando que a ideia principal dessa categoria leva em conta o contexto socioambiental local, que abrange circunstâncias sociais, políticas, econômicas, culturais e o contexto eco-físico, sem deixar de considerar a inter-relação com o contexto global em que se inserem, são apresentadas a seguir duas das seis unidades destacadas na pesquisa que evidenciam a incorporação de problemáticas locais ou a presença significativa de outros campos de conhecimento (especialmente que permitem uma compreensão global do problema):

[...] Populaçáo Humana: crescimento populacional humano; [...] caracterização da planície costeira do Rio Grande do Sul; alteraçôes climáticas globais; efeito estufa; vídeo-discussão; energia e sociedade; alternativas energéticas; a água na natureza e o ciclo da água; a crise da água: causas e consequências; introdução a poluição I; lixo e reciclagem; introduçáo a poluição II; poluiçáo aquática e atmosférica; princípios de biologia da conservaçáo e manutenção da biodiversidade; [...] aspectos gerais da Proteçáo ambiental no Brasil (unidade C-5.1).

[...] mapeamento de diferentes campos de atuação profissional na área das atividades de Lazer e dos Esportes e Atividades de Aventura na natureza em Belo Horizonte; planejamento e organizaçấo de atividades de lazer e esporte na natureza; planejamento de intervenção educativa através das atividades de lazer na natureza (unidade C-8.2).

O questionamento de problemas locais diante dos contextos mais amplos da problemática ambiental em âmbito global surge como preocupação dos discursos ambientais desde a elaboração dos primeiros documentos redigidos em encontros que configuraram a problemática ambiental como questáo emergente ainda no início dos anos $1970^{26}$. Nessa mesma época tal preocupação ganha destaque ainda maior com o fortalecimento dos discursos críticos que rogavam pela "aprendizagem significativa", implicando no desenvolvimento de problemas "concretos" para o indivíduo, ou seja, que partiam de suas experiências cotidianas no ambiente local ${ }^{26}$. Considerando o significativo desenvolvimento histórico dessa questão nos discursos ambientais destaca-se a pequena presença de unidades de significado destacadas do "corpus" de análise que se associam a essa categoria.

\section{Categoria 5 - Levar em conta o sujeito na construção do conhecimento}

Os critérios dessa categoria estão associados à importância da utilização de diversas estratégias para favorecer a participaçáo ativa por parte dos alunos no processo de educação ambiental, o que implica na consideraçáo do papel do sujeito no processo de construçáo do conhecimento, levando em conta o sujeito (indivíduo ou grupo) na definição e no desenvolvimento de conteúdos, metodologias e projetos.

Não há evidência em nenhum dos planos de ensino sobre a participação ativa dos sujeitos participantes na construção das disciplinas (especialmente no que se trata a procedimentos metodológicos e tipologia ou critérios de avaliação). Foram destacadas unidades que ressaltam proposiçóes de temas para seminários, planejamento de planos de aula e inserçóes em campo pelas quais o sujeito participa (pelo menos em parte) da construção de conteúdos da disciplina; há também uma unidade que destaca a construção de um blog, também associado à construção de conteúdos:

Aulas expositivas e dialógicas, exibição de documentários, leitura e debate de textos, seminários de apresentaçáo de textos, planejamento e apresentaçáo de planos de aula, vivencias em atividades de campo (unidade M-8.1).

Exposição dialogada; pesquisas bibliográficas; organizaçáo/proposição de temas para seminários, debates e dramatizaçóes; (...) inserção em campo (unidade M-9.1).

Materializar os diálogos construídos durante a disciplina, na sistematização de textos escritos, utilizando como ferramenta pedagógica um blog específico para o debate, socialização de ideias, imagens, produção de análise individual e coletivamente (unidade O-12.2).

A preocupação com a maior participação do aluno no processo de construção do conhecimento é destacada, especialmente, pelos questionamentos de discursos críticos a modelos fundamentados em abordagens tecnocráticas ou que se associavam às ciências aplicadas com linearidade para "implementaçôes" e "prescriçóes" sobre o conhecimento e sobre o meio ambiente. Considerando a persistência de uma significativa lacuna entre a teoria e a prática nos discursos críticos, esses questionamentos são "revisitados" no desenvolvimento de abordagens pós-críticas", principalmente pela busca mais "modesta" de um "re-imaginar" dos interesses do 
conhecimento, da crítica das ideologias, das relações de poder e das condiçóes opressivas enfatizadas na de certa forma "utópica" perspectiva socialmente crítica $^{27}$. Considerando o significativo desenvolvimento histórico dessa questão tanto em abordagens críticas como em abordagens pós-críticas do campo ambiental destaca-se, mais uma vez, a pequena presença de unidades de significado destacadas do "corpus" de análise que se associam a essa categoria.

\section{Categoria 6 - Considerar os aspectos cognitivos e afetivos, éticos e estéticos}

Os critérios dessa categoria estão associados ao apoio para um "desenvolvimento integral" dos alunos na perspectiva da aquisição crítica de saberes múltiplos, o que inclui aspectos materiais, estruturais, pedagógicos e psicológicos, considerando ainda seus interesses, suas capacidades e dificuldades. São apresentadas a seguir três das 17 unidades destacadas na pesquisa que evidenciam o apoio psicológico, pedagógico e econômico aos alunos; a intencionalidade explicitada para trabalhar aspectos não conceituais exclusivamente; a valorização das diversas formas de conhecimento; $o$ estímulo às diferentes linguagens (diferentes maneiras de expressão, como artística, visual, etc.); ou ainda $o$ reconhecimento das diferenças e da pluriculturalidade:

A disciplina de Educação Física e Meio Ambiente compreende o estudo, análise e proposiçóes ambientais através da Educação Física no ensino formal, não formal e informal (unidade E-2.1).

Compreender o Esporte na Natureza enquanto fenômeno sócio-cultural de múltiplas possibilidades, diferenciando-o de práticas esportivizadas e ressaltando a diversidade de suas modalidades; refletir sobre a capacitaçấo do professor de Educaçâo Física para atuar nesse segmento, proporcionando fundamentos básicos para o planejamento e elaboração de propostas pedagógicas e programas de Esportes na Natureza (unidade O-10.1).

Exposição dialogada; Seminários de estudos realizados em grupo; Trabalhos individuais e coletivos; Leituras de textos; Realizaçóes de pesquisas; vivências com atividades práticas, individuais e em grupo; Assistência a filmes; produção de textos; histórico, conceitos e consideraçôes gerais acerca do Lazer, Recreação e Turismo Esportivo (unidade C-12.1).

Há, de maneira geral, uma boa diversidade de propostas nos planos de ensino analisados que destacam estratégias que potencialmente contribuem para o desenvolvimento de aspectos não conceituais exclusivamente, assim como para a valorizaçáo de diferentes formas de conhecimento e de diferentes linguagens. Essa valorizaçáo da alteridade/diferença/pluralidade também aparece como característica de desenvolvimentos pós-críticos do campo ambiental, configurando-se numa busca democrática pelo aumento da inclusão social igualitária/justa, muitas vezes celebrada ou imaginada em pedagogia como uma abertura mais heterogênea das "diferentes maneiras de saber" e, em alguns casos, "diferentes maneiras de fazer e ser/existir"

\section{Categoria 7 - Coerência e reconstrução entre teoria e prática}

Considerando que essa categoria se associa à articulaçáo entre teoria e prática como duas formas necessariamente complementares de criação dinâmica do conhecimento, são apresentadas a seguir três das 15 unidades destacadas na pesquisa que evidenciem a existência de trabalhos práticos coerentes com as propostas teóricas ou trocas produzidas na teoria e na prática a partir da experiência:

Conhecer, organizar e praticar Atividades Físicas de Aventura na Natureza (unidade O-1.3).

Planejar, organizar e executar atividades físicas na natureza ou ao ar livre (unidade O-3.3).

Identificar e discutir a produção acadêmica que trata das relaçôes entre lazer, meio ambiente e atividades e esportes de aventura na natureza; possibilitar a vivência das atividades esportivas e de lazer na natureza; analisar possibilidades de intervenção profissional e educativa, através das atividades de lazer e esportes de aventura na natureza (unidade O-8.2).

As unidades de significado destacadas colocam em evidência as atividades na natureza, uma vez que essas podem estabelecer interessantes caminhos para a articulação entre a teoria e a prática, desde que compreendidas como experiências pedagógicas que podem contribuir para uma formação humana mais ampliada, tematizando questóes fundamentais frente à crise socioambiental. Novamente essa possibilidade se depara com a questão sobre a dualidade de possibilidades associadas às práticas esportivas e recreativas, como previamente discutido na apresentação da categoria 1 .

De certa forma, essa questáo vem se desdobrando de maneira particular nas atividades na natureza. Nas últimas décadas constata-se um grande crescimento da 
procura pelas práticas de lazer que de alguma forma estão associadas ao "ambiental" (sobretudo fora do meio urbano), em grande parte por causa da criação de um imaginário de modernidade e saúde associado a essas práticas $^{28}$. No entanto, quando associadas à indústria do lazer, essas práticas são geralmente oferecidas como "mercadoria" ou como elemento "compensatório" para a vida estressante do meio urbano, fortalecendo a ideia de uma natureza como um espaço alternativo, geralmente ligado a um ideal de beleza e bem-estar.

\section{Categoria 8 - Orientação prospectiva de cenários alternativos}

Essa categoria está associada à proposta de construção de novas visóes de ciência/sociedade/tecnologia/ambiente na perspectiva de uma participação responsável e da formação de profissionais críticos, abertos para novas experiências e para propostas alternativas de gestão das relaçóes sociedade-natureza.

Destacam-se nesse sentido práticas sociais que explicitam e reduzem as relaçóes discriminatórias e predatórias, especialmente por meio da inclusão das populaçóes marginalizadas nas atividades esportivas e de lazer. Além dessa característica, são apresentadas a seguir duas das sete unidades destacadas dos planos de ensino que evidenciam a preocupação com a formação de profissionais comprometidos com as geraçóes futuras, além da análise critica do conhecimento cientifico e tecnológico (passado e presente) que influencia cenários futuros:

Atividades físicas e esportes no meio natural; excursionismo, acampamentos, caminhadas, pedaladas e remadas; condutas de mínimo impacto no ambiente natural; (unidade C-1.1).

Lazer e meio ambiente; lazer, ecologia e desenvolvimento sustentável (unidade C-8.1).

As unidades de significado que se associam a essa categoria destacam, no geral, conceitos que se desdobram sobre o campo discursivo da "sustentabilidade" e do "desenvolvimento sustentável", por exemplo, as condutas de mínimo impacto que aparece na unidade C-1.1 destacada acima. Na década de 2000 o crescente uso do termo "sustentabilidade" atraiu amplo debate e crítica nos círculos de educação ambiental. No núcleo dessas críticas se encontram afirmações como: "o conceito de sustentabilidade é muito abstrato ou muito amplo"; ou "instituiçôes não contam com profissionais para atuar nessa área”; ou ainda "a inserção da sustentabilidade exige recursos significativos que as instituiçóes não possuem" 29 .
Já o conceito de "desenvolvimento sustentável" que aparece como um possível novo marco conceitual e discursivo para a educação (ambiental) é fruto de um contexto sociocultural distante daquele que o originou na regiáo latino-americana; assim, propostas de nomes que adotam esse conceito, como de "educação para o desenvolvimento sustentável" ou de "educação para um futuro sustentável", têm sido muito criticadas, pois possivelmente póem em risco uma identidade, uma tradição e um capital simbólico que têm sustentado certa utopia ambiental de luta contra-hegemônica e emancipatória para capitular diante deste instável conceito que nasce do coração do "status quo", largamente associado pela crítica ecológica como uma das raízes dos problemas socioambientais ${ }^{30}$. Essas questóes precisam ser relevadas cuidadosamente ao analisar propostas de institucionalização da dimensão ambiental (inclusive no currículo), levando em consideração a comum tendência a práticas de "greenwashing", problemática já abordada na introdução desse artigo.

\section{Categoria 9 - Adequação metodológica}

Essa categoria está associada à verificação da consistência, a ética e o rigor entre as metas e os meios que se propóem para alcançá-las. Nesse sentido, apresenta-se a seguir uma das oito unidades destacadas dos planos de ensino que evidenciam a articulação entre conteúdos e metodologias, a presença de estudos de campo e a utilização de metodologias participativas:

Aulas expositivas; utilização de recursos audiovisuais; discussóes de texto e debates; dinâmicas de grupo e vivências lúdicas; vivência dos aspectos técnicos e pedagógicos relacionados ao conteúdo abordado; saídas a campo (unidade M-10.1).

Um dos mais clássicos problemas do campo educacional é a distância entre propostas teóricas e suas reais possibilidades práticas. A comum falta de consistência entre metas estabelecidas e os meios propostos para alcançá-las é parte essencial do problema. A questão se torna ainda mais complexa com a contínua emergência de novos embates e "tensões" de discursos cada vez mais complexos. Desse modo, uma das principais preocupaçóes das abordagens pós-críticas faz referência a como o teórico de currículo pós-crítico lida com as subjetividades, tais como: tensões locais/nacionais/regionais/globais; materialismos históricos/geográficos/culturais; variaçôes geo-epistemologicamente conduzidas; o cada vez mais cosmopolita e dinâmico/fluido professor, aluno, pesquisador e pesquisado; textos 
e discursos que abrangem cada vez mais contextos virtuais. Sobretudo, a ("bagunçada") política de múltiplas ontologias-epistemologias é reconhecida; limites são reconhecidos; lacunas entre a teoria e a prática, os dualismos corpo-mente e as contradiçóes de meu/nosso mundo (individual/coletivo) são conciliados ${ }^{27}$. Apesar de algumas indicaçóes em direçâo à presença de estudos de campo e para a utilizaçáo de metodologias participativas, são praticamente inexistentes nos textos elementos que indiquem coerência entre metodologias participativas, metas e proposições para alcançá-las.

\section{Categoria 10 - Espaços de reflexão e participação democrática}

A proposta dessa categoria se associa à promoção de encontros que garantam aproximaçóes entre indivíduos e grupos (especialmente) de diferentes origens objetivando a troca na diversidade. Nesse sentido, as unidades destacadas na pesquisa

\section{Discussão}

A análise dos planos de ensino evidencia, acima de qualquer outra coisa, como as práticas esportivas e recreativas na natureza aparecem como foco quase que exclusivo de boa parte das disciplinas, nas quais as discussóes sobre as sinergias entre a Educação Física (num contexto mais amplo) e as questôes ambientais ocupam pouco ou nenhum espaço. A presença dessa temática nos currículos de Educação Física é evidência de que as discussóes envolvendo contextos de atividades esportivas e recreativas na natureza surgiram e ganharam força (tanto em eventos como em publicaçóes científicas) num momento anterior do que as discussóes envolvendo as questôes ambientais e a Educação Física num contexto mais amplo. Dessa maneira, não deveria ser surpresa que a institucionalização das questóes envolvendo as atividades esportivas e recreativas na natureza nos currículos de Educação Física tenham também acontecido num momento anterior, consolidando-se como foco de boa parte das disciplinas ainda hoje.

Ainda nesse sentido, destaca-se o bom número de disciplinas nos currículos de Educação Física no ensino superior brasileiro que abordam mais especificamente diferentes modalidades esportivas e recreativas na natureza, evidenciando ainda mais a "vantagem" histórica que essa temática possui ressaltam os jogos e o esporte do ponto de vista social, além de práticas de trabalhos participativos e colaborativos, diferentes formas de construção do currículo (aberto ou fechado, incluindo possibilidades de trabalhos de campo, em grupo, etc.) e metodologias de reflexão e participação. Segue um exemplo entre as 14 unidades destacadas na pesquisa dentro dessa categoria:

Fundamentação básica e vivência prática de diferentes atividades físicas de aventura na natureza; Atividades físicas na natureza: classificação e perspectivas de intervençáo (unidade E-6.3).

Como já discutido na apresentação de categorias anteriores, os jogos, esportes e atividades em contextos de lazer oferecem interessantes possibilidades de diálogos na diversidade em contextos de "com-vivência". No entanto essas possibilidades se deparam com a questão sobre a potencial dualidade dessas práticas, que podem se manifestar tanto como questionamento como reforço de paradigmas (dominantes) vigentes.

em relação às discussóes envolvendo as questôes ambientais num contexto mais amplo na Educação Física. Aliás, essa história relativamente mais antiga da temática e o consequente volume de produçôes acadêmicas em parte explicam a diversidade de nomenclaturas utilizadas para a descrição das atividades na natureza, uma vez que diferentes atores se posicionam diferentemente diante dos embates desse espaço de disputa e isso se reflete, inclusive, nas nomenclaturas utilizadas. Essa diversidade é evidente nas próprias nomenclaturas das disciplinas analisadas nessa pesquisa - Atividades Físicas de Ação na $\mathrm{Na}$ tureza; Atividades Físicas e Esportivas na Natureza; Esportes de Aventura; Atividades Físicas na Natureza.

De maneira geral, considerando a própria historicidade do tema, seu alcance (relativamente) global e o crescente espaço que ocupa em produçóes científicas de todos os tipos sustentam os discursos que clamam por sua institucionalização no currículo da Educação Física no ensino superior. No entanto, há importantes consideraçóes acerca das limitaçóes críticas de abordagens/propostas que buscam a inserção das questôes ambientais por meio das atividades esportivas e recreativas na natureza ${ }^{31-33}$ e essas limitações parecem se engrandecer diante de abordagens caracterizadas como "técnicas" ou 
“esportivizadas” que com frequência reproduzem paradigmas históricos (especialmente associados a raízes materialistas/militaristas/higienistas da Educação Física) que reforçam a legitimação/perpetuação de símbolos de dominância. Considerando as disciplinas que fazem parte do "corpus" de análise dessa pesquisa esse tipo de abordagem ainda parece estar bem presentes nos currículos de Educação Física.

No sentido contrário, a disciplina 5 tem como foco único as questóes ambientais e o desenvolvimento de conceitos da ecologia. A proposta de inserção dessa disciplina na matriz curricular do curso de Educação Física não contempla a ideia de interdisciplinaridade da educação ambiental, que está muito mais associada ao "diálogo" entre as questôes ambientais e as particularidades de cada área do que a simples inserção da temática ambiental nos currículos dos diversos cursos. Considerando a histórica relação da instituição em que essa disciplina é ministrada com o desenvolvimento do campo ambiental, compreende-se a importância (acadêmica/política) da inserção dessa disciplina no currículo de Educação Física. No entanto, sem uma contextualização sobre as particularidades geo-culturais/históricas da Educação Física, fica a questão de quanto ou como a apreensão desses conceitos e dimensóes da ecologia contribui para a formação profissional do educador físico.

Esse desejado diálogo interdisciplinar e transversal parece estar mais próximo de outros exemplos evidenciados pela análise dos planos de ensino que apresentam relaçóes mais "claras" entre as questóes ambientais e as particularidades da Educação Física. Esses exemplos serão apresentados a seguir, com a devida atenção a potenciais fatores limitantes com base nas discussões desenroladas na apresentação dos resultados (seção anterior): apesar da disciplina 2 apresentar interessantes encontros entre as questóes ambientais e a Educação Física, não faz referências às atividades na natureza (como já discutido, tópico importante diante das sinergias educação física-meio ambiente). Essa disciplina poderia ser bem complementada pela disciplina 1, que foca as atividades na natureza e aparece no currículo de Educação Física da mesma universidade. No entanto, a disciplina 1 está presente no currículo das turmas de bacharelado, enquanto que a disciplina 2 aparece nos currículos de licenciatura, uma clara evidência da distinção entre "profissionais da prática" (bacharel) e "profissionais da teoria" (licenciado) comumente presente na Educação Físicai. Já a disciplina 3, também encontrada no currículo de Educação Física dessa mesma universidade (licenciatura noturno), traz em seu plano de ensino todos esses elementos (educação física, educação ambiental e as atividades na natureza), constituindo-se como interessante proposta diante das perspectivas de ambientalização curricular na Educação Física. Importante ressaltar que as três disciplinas (1, 2 e 3) são obrigatórias.

Também apresentando relação mais próxima entre as questốes ambientais e as particularidades $\mathrm{da}$ Educação Física destacam-se as disciplinas 6, 8, 9, 10 e 13. Destas, apenas a disciplina 9 não apresenta elementos das atividades esportivas e recreativas na natureza. Porém, no currículo de Educação Física da mesma universidade há a disciplina 10 que, apesar de também apresentar elementos específicos das relações entre Educação Física e educação ambiental, tem como foco principal as atividades na natureza. Dessa maneira, é possível afirmar que a união entre essas duas disciplinas constituem um dos melhores exemplos de ambientalização de currículos de Educação Física da amostra dessa pesquisa. No entanto, ambas as disciplinas são optativas, o que significa que o aluno do curso pode completar sua graduação sem nunca entrar em contato com elas.

Outro ponto que merece destaque na análise dos planos de ensino é a diversidade de objetivos, conteúdos e metodologias utilizadas nas diferentes disciplinas. Essa amplitude de metas e conteúdos reflete o que tipicamente ocorre no campo ambiental. A consideração de que a constituição do campo ambiental como área de conhecimento é relativamente recente é um dos motivos pela complexidade dos conceitos e pela diversidade de compreensóes associadas à dimensão ambiental. Como consequência, há uma aparente falta de identidade epistemológica na qual a educação ambiental possa se "situar" dificultando, inclusive, uma atuação para além de uma visão meramente ecologizante e de práticas sociais pontuadas ${ }^{7}$.

A diversidade de objetivos e conteúdos encontrada nos planos de ensino também reflete em parte as diferenças entre as escolas, centros e institutos aos quais os cursos de Educação Física estão associados. Essa variedade é fruto das evoluçóes históricas da área, desde suas raízes mais associadas à saúde e às ciências biológicas até manifestações mais "modernas" associadas às ciências humanas. No próprio "corpus" de análise dessa pesquisa há exemplos de cursos associados a centros e institutos de ciências biológicas, da saúde e de educação, além de unidades de ensino que já conquistaram certa "independência” como escolas de Educação Física. Claramente os diferentes/particulares interesses geo-culturais/ históricos desses centros e institutos influenciam nos 
objetivos e conteúdos dos cursos associados a eles, e essas diferenças aparecem nos planos de ensino das disciplinas que compóem o quadro curricular.

Entre as consideraçóes sobre essa amplitude de definições, conceituaçôes, características, dimensões e qualidades associadas aos objetivos e conteúdos que compóem as propostas curriculares talvez a mais preocupantes seja a falta de uma base epistemológica ou mesmo de "lugares comuns" que poderiam oferecer referencias mais consistentes na construção de novos/ diferentes diálogos entre o campo da Educação Física e o campo ambiental. Por um lado, há uma multiplicidade quase que inapreensível de caminhos possíveis, tais como: o estímulo por encontros críticos entre o ser humano e a natureza por meio das atividades na natureza e jogos de sensibilização; o questionamento de padróes modernos da relaçáo ser humano-natureza por meio das diversas modalidades esportivas (incluindo os esportes na natureza); o estímulo a discussóes críticas sobre a inclusão de populaçóes marginalizadas por meio de atividades que focam questōes relacionadas ao direito à saúde e ao lazer; entre outras destacadas na apresentação dos resultados. Por outro lado, alguns dos principais elementos apontados pelas pesquisas no campo ambiental e no próprio campo da Educação Física não aparecem nos planos de ensino analisados, tais como: a participação ativa dos sujeitos envolvidos na construção das disciplinas (especialmente no que se trata a procedimentos metodológicos e tipologia ou critérios de avaliação); referências à "teoria da complexidade" ou mesmo à "complexidade" como referida por Edgar Morin e seus seguidores, sendo que essa referência aparece com muita frequência em publicaçóes do campo ambiental, especialmente em contextos latinos; os jogos cooperativos e os jogos tradicionais como caminhos potenciais para o diálogo com atividades associadas a diferentes ideias e posiçôes filosóficas, nesse caso, do campo ambiental, apesar do destaque dado a essas atividades em publicaçóes da Educação Física, inclusive em propostas de inserção da dimensão ambiental na área.
Mudando o foco para as características da Rede ACES, referencial escolhido como "benchmark" para esse estudo, esperar-se-ia que pelo menos os conceitos chaves de cada categoria fossem contemplados pelas propostas presentes em planos de ensino de disciplinas que propóem um diálogo entre o campo ambiental e o campo da Educação Física, considerando que a Rede traz em suas definiçốes o resultado de embates históricos em torno da emergência e legitimação de elementos que constituem os atuais conceitos sobre o "ambiental". No entanto, pode-se observar na apresentação dos resultados que essa realidade é mais exceção do que regra.

O mesmo pode ser dito sobre as pesquisas no próprio campo da Educação Física. Mesmo que incipiente, há uma produção crescente de pesquisas que buscam compreender melhor as possibilidades de inserção da dimensão ambiental nos currículos da educação física. Boa parte dessas pesquisas são, inclusive, publicadas nos próprios veículos da área de Educaçâo Física ${ }^{26}$. Talvez a principal contribuição dessas pesquisas seja o levantamento de elementos particulares da Educação Física que contribuam para o contexto mais amplo da interação ser humano(sociedade)-meio ambiente(natureza), contribuindo para a própria emergência de novos questionamento sobre o "ambiental". No entanto, algumas das principais particularidades da Educação Física apontadas pelas pesquisas nesse sentido, tais como os jogos cooperativos e os jogos tradicionais e a compreensão da cultura de movimento - ideia recorrente inclusive nos $\mathrm{PCN}$ para a Educação Física $^{34}$ - não aparecem nos planos de ensino analisados.

Analisando o cenário mais amplo, o campo da Educação Física parece ainda carente de espaços que possibilitem encontros mais significativos entre o que acontece nos contextos da pesquisa e no âmbito do ensino em contextos de ambientalização curricular. Esses encontros são essenciais para o fortalecimento da questão na área e, possivelmente, para a eventual legitimação da Educação Física como ator expressivo nas disputas que fazem parte da constituição do "ambiental".

\section{Notas}

a. As Universidades participantes são: Universitat Autònoma de Barcelona (UAB - Espanha); Universidad Nacional de San Luis (UNSL - Argentina); Universidad Nacional de Cuyo (UNCu - Argentina); Universidade Federal de São Carlos (UFSCar - Brasil); Universidade Estadual Paulista, Campus Rio Claro (UNESP - Rio Claro - Brasil); Universidade Estadual de Campinas (UNICAMP - Brasil); Universidad de Pinar del Río (UPR - Cuba); Universidade de Aveiro (UA - Portugal); Universitat de Girona (UdG - Espanha); Technical University Hamburg (TUTECH - Alemanha); Universitá degli studi del Sannio (UNISANNIO - Itália). 
b. Para leitura mais aprofundada sobre os documentos nacionais e internacionais que rogam pela inclusão da dimensão ambiental nos currículos do ensino superior sugere-se a leitura de RoDRIGUEs ${ }^{26}$ (principalmente páginas 66 a 69).

c. O termo "greenwashing" (tradução literal seria algo como "lavagem verde") é usado na língua inglesa para se referir a uma estratégia de "marketing" "verde" maliciosamente/enganosamente usada para promover a percepção de que os objetivos e políticas de uma organização são ambientalmente corretas/amigáveis.

d. Sítio eletrônico: http://www.education.monash.edu.au/research/groups/edu-env-sustainability/.

e. Sítio eletrônico: http://grupcomplex.uab.cat/.

f. Para uma melhor compreensão sobre a teoria da complexidade e sua relação com as dinâmicas sociais sugere-se a leitura de Morin ${ }^{35}$ e Bonil et al. ${ }^{36}$. Para um enfoque mais específico sobre a educação para a sustentabilidade a partir da perspectiva da complexidade sugere-se a leitura de Bonil et al. ${ }^{37}$.

g. A apresentação do termo dessa maneira justifica-se pela necessidade de enfatizar o caráter humano implícito na expressão, ou seja, enfatizar o "viver com", que significa considerar a complexa teia de relaçóes de seres humanos sendo-uns-com-os-outros. O caráter dinâmico da expressão também deve ser salientado, apresentado especialmente pelo uso do hífen (usual principalmente na fenomenologia), pois homens e mulheres não são no mundo como objetos estáticos, estão sendo no mundo num movimento constante e transformador ${ }^{38}$.

h. Segundo Payne e Rodrigues ${ }^{27}$, após um processo inicial de teorização de um discurso crítico, do desenvolvimento profissional e da ação e pesquisa participativa em educação ambiental, uma transição mais recente para um enquadramento "pós-crítico" de investigação e inquérito ocorreu em meados da década de 90, parcialmente como resposta ao interesse teórico no pós-estruturalismo ${ }^{39}$, incluindo perspectivas feministas ${ }^{40-41}$ e um interesse renovado em abordagens fenomenológicas ${ }^{42}$.

i. Para leitura mais aprofundada sobre esse paradigma historicamente constituído na área da Educação Física sugere-se a leitura de Borges ${ }^{43}$.

\begin{abstract}
Curricular environmentalization in Physical Education programs in Brazilian Federal Universities

The aim of the paper was to analyze evidences of curricular environmentalization in physical education programs in higher education settings in Brazil. Accordingly, the corpus of analysis was composed by guides of academic units that address environmental issues in physical education programs of Federal Universities in Brazil. The corpus was analyzed through Discursive Textual Analysis, methodology that comprises: a) disassembling of written texts ("unitarization"); b) establishing relations (categorization); c) capturing of an emerging novelty (original "metatext"). The "units of meaning" highlighted during the unitarization step were organized into predefined categories based on characteristics framed by the ACES Network for an environmentalized study. This benchmark was chosen due to its academic strength in front of the environmental field, presenting itself as a significant current social (con)text and bringing in its definitions results of historical clashes surrounding the emergency/legitimation of elements that constitute contemporary concepts about the "environment". Thus, it should be expected that at least the key concepts of each category were embraced by academic units that propose a dialogue between the environmental field and the field of physical education. However, the results of this research show a very different reality, putting in evidence sportive and recreational activities in nature as the almost exclusive focus of academic units that address environmental issues in physical education programs of Federal Universities in Brazil. Furthermore, the paper's conclusive arguments present significant evidences about the dimensions of environmental discourses that are being incorporated by physical education curricula in higher education settings, as well as new/"alternative" perspectives that emerge when the environmental and the physical education fields cross paths.
\end{abstract}

KEY WoRDS: Curriculum; Higher education; Environment; Formal education. 


\section{Referências}

1. Oliveira HT, Farias CRO, Pavesi A. Educação ambiental no ensino superior brasileiro: caminhos percorridos e perspectivas para políticas públicas. Rev Bras Educ Ambient. 2008;3:91-101.

2. Ferraro Júnior LA. A universidade e a formação do educador ambiental: uma breve reflexão sobre as experiências da Universidade Estadual de Feira de Santana - UEFS. Rev Bras Educ Ambient. 2004;1:116-9.

3. Verdi M, Pereira GR. A educação ambiental na formação de educadores: o caso da Universidade Regional de Blumenau - FURB. Revista FURB. 2006;17:375-91.

4. Pavesi A. A ambientalização da formação do arquiteto: o caso do curso de arquitetura da Escola de Engenharia de São Carlos (CAU, EESC-USP) [tese]. São Carlos (SP): Universidade Federal de São Carlos; 2007.

5. Freitas D, Zuin VG, Pavesi A. A inserção da dimensão ambiental na formação de professores. In: Abramowicz A, Passos CLB, Oliveira RMMA, editores. Desafios e perspectivas das práticas em educação e da formação de professores. São Carlos: Pedro e João; 2007. p.233.

6. Zuin VG, Farias CRO, Freitas D. A ambientalização curricular na formação inicial de professores de química: consideraçôes sobre uma experiência brasileira. Rev Electrón Ensen. Cienc. 2009;8:552-70.

7. Rosalem BM, Barolli E. Ambientalização curricular na formação inicial de professores: o curso de pedagogia da FE-UNICAMP. Rev Bras Educ Ambient. 2010;5:26-36.

8. Freitas D, Souza ML. O ensino superior no Brasil: desafios para a ambientalizaçáo curricular. In: Leme PCS, Pavesi A, Alba D, González MJD. Visões e experiências ibero-americanas de sustentabilidade nas universidades. São Paulo: USP; 2012. p.129-36.

9. Órgão Gestor da Política Nacional de Educação Ambiental. Mapeamento da educação ambiental em instituiçóes brasileiras de educação superior: elementos para políticas públicas. Brasília: MMA/ME; 2007. (Série Documentos Técnicos; 12).

10. Bursztyn M. Meio ambiente e interdisciplinaridade: desafios ao mundo acadêmico. Desenvolv Meio Ambient. 2004;10:67-76.

11. Farias CRO. A produção da política curricular nacional para a educação superior diante do acontecimento ambiental: problematizaçóes e desafios [tese]. Sáo Carlos (SP): Universidade Federal de São Carlos; 2008.

12. Junyent M, Geli AM, Arbat E, editores. Ambientalización curricular de los estudios superiores: proceso de caracterización de la ambientalización curricular de los estudios universitarios. Girona: Universitat de Girona-Red ACES; 2003. (Colección Diversitas; 40).

13. Brasil. Ministério da Educação. Secretaria de Educação Fundamental. Parâmetros curriculares nacionais. Brasília: MEC/SEF; 1998.

14. Brasil. Lei 9.795, de 27.04.1999. Dispóe sobre Educação Ambiental e institui a Política Nacional de Educação Ambiental, e dá outras providências. Diário Oficial da União, Brasília (28 abr. 1999);Sec,1:138. [citado 16 dez. 2012]. Disponível em: http://www.mpambiental.org/?acao=legislacao-pop\&cod=322.

15. Arbat E, Geli AM, editores. Ambientalización curricular de los estudios superiores: aspectos ambientales de las universidades. Girona: Universitat de Girona-Red ACES; 2002. (Colección Diversitas; 32).

16. Geli AM, Junyent M, Sánchez S, editores. Ambientalización curricular de los estudios superiores: acciones de intervención y balance final del proyecto de ambientalización curricular de los estudios superiores. Girona: Universitat de Girona-Red ACES; 2004. (Colección Diversitas; 49).

17. Geli AM, Junyent M, Sánchez S, editores. Ambientalización curricular de los estudios superiores: diagnóstico de la ambientalización curricular de los estudios superiores. Girona: Universitat de Girona-Red ACES; 2003 (Colección Diversitas; 46).

18. Payne PG. Evaluating VCE outdoor education: a partial response to Robbo Bennetts. Journeys. 2001;6:15-8.

19. Moraes R. Uma tempestade de luz: a compreensão possibilitada pela análise textual discursiva. Cienc Educ. 2003;9:191-211.

20. Soares CL. Educação física: raízes européias e Brasil. 2a ed. Campinas: Autores Associados; 2001.

21. Marcellino NC. Lazer e educação. 6a ed. Campinas: Papirus; 2000.

22. Bracht V. A criança que pratica esporte respeita as regras do jogo... capitalista. Rev Bras Ciênc Esporte. 1986;7:62-8.

23. Osborne R, Batista WA. Educação física na década da educação para o desenvolvimento sustentável. Motriz. 2010;16:28-36.

24. Kishimoto TM. Jogos tradicionais infantis. Petrópolis: Vozes; 1993.

25. Brotto FO. Jogos cooperativos: se o importante é competir, o fundamental é cooperar. Santos: Re-novada; 1997.

26. Rodrigues C. A ambientalização curricular da educação física nos contextos da pesquisa acadêmica e do ensino superior [tese]. São Carlos (SP): Universidade Federal de São Carlos; 2013. 
27. Payne PG, Rodrigues C. Environmentalizing the curriculum: a critical dialogue of south-north framings. Perspect. 2012;30:411-44.

28. Sampaio TMV. Educação física, lazer e meio ambiente: desafios da relação ser humano e ecossistema. In: Marco A, editor. Educação física: cultura e sociedade. Campinas: Papirus; 2006.

29. Leal Filho W. Dealing with misconceptions on the concept of sustainability. Int J Sustain Higher Educ. 2000;1:9-19.

30. Carvalho ICM. O ambiental como valor substantivo: uma reflexão sobre a identidade da educação ambiental. In: Sauvé L, Orellana I, Sato M. Textos escolhidos em educação ambiental: de uma América à outra. Montreal: Publications ERE-UQAM, 2002. p.85-90.

31. Rodrigues C. Observando os "estudos do meio" pela lente da educação ambiental crítica. Rev Eletrôn Mestr Educ Ambient. 2010;24:503-17.

32. Rodrigues C. A ambientalização dos currículos de educação física no ensino superior. Motriz. 2012;18:557-70.

33. Rodrigues C. As práticas de lazer diante do acontecimento ambiental: processos de ambientalização e a compreensão do lazer enquanto prática social. Licere. 2012;15:1-22.

34. Brasil. Ministério da Educação. Secretaria de Educação Fundamental. Parâmetros curriculares nacionais - terceiro e quarto ciclos do ensino fundamental: educação física. Brasília: MEC/SEF; 1998.

35. Morin E. Introdução ao pensamento complexo. Lisboa: Instituto Piaget; 1991.

36. Bonil J, Sanmartí N, Tomás C, Pujol RM. Un nuevo marco para orientar respuestas a las dinámicas sociales: el paradigma de la complejidad. Invest Esc. 2004;53:5-20.

37. Bonil J, Junyent M, Pujol RM. Educación para la sostenibilidad desde la perspectiva de la complejidad. Rev Eureka Enseñ Divulg Cienc. 2010;7:198-215.

38. Stevaux RP, Rodrigues C. Com-vivência, educação e lazer: construindo processos educativos a partir da diversidade cultural. 6. Colóquio Internacional Educação e Contemporaneidade; 20 set-22 2012; São Cristóvão, BR. São Cristovão: EDUCON; 2012.

39. Gough N. Playing at catastrophe: ecopolitical education after poststructuralism. Educ Theory. 1994;44:189-210.

40. Greenall Gough A. Founders in environmental education. Geelong: Deakin University; 1993.

41. Barron D. Gendering environmental education reform: identifying the constitutive power of environmental discourses. Aust J Environ Educ. 1995;11:107-20.

42. Payne PG. Ontology and the critical discourse of environmental education. Aust J Environ Educ. 1995;11:83-106.

43. Borges CMF. O professor de educação física e a construção do saber. 2a ed. Campinas: Papirus; 2001.

\section{Agradecimentos}

Agradeço aos professores, secretários e coordenadores dos cursos de Educação Física que atenciosamente colaboraram com a coleta de dados da pesquisa apresentada no presente artigo.

Agradeço à Professora Dra. Denise de Freitas e ao Professor Dr. Phillip G. Payne pela orientação em minha Tese de Doutorado da qual fez parte a pesquisa apresentada no presente artigo.

O presente trabalho foi realizado com apoio do CNPq, Conselho Nacional de Desenvolvimento Científico e Tecnológico - Brasil.

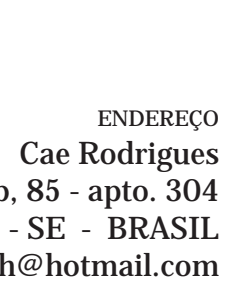

Av. Lions Club, 85 - apto 304

49037-420 - Aracaju - SE - BRASIL e-mail: cae_jah@hotmail.com
Recebido para publicação: 12/06/2013

1a. Revisão: 24/03/2014

2a. Revisão: 06/11/2014

Aceito: 07/ 11/ 2014 